\title{
ELECTORAL UNCERTAINTY, FISCAL POLICIES \& GROWTH: Theory and evidence from Germany, the UK and the US
}

\author{
George Economides \\ Athens University of Economics and Business \\ Jim Malley \\ University of Glasgow, and CESifo \\ Apostolis Philippopoulos* \\ Athens University of Economics and Business, and CESifo \\ Ulrich Woitek \\ University of Munich, and CESifo
}

September 28, 2003

\begin{abstract}
In this paper we study the link between elections, fiscal policy and economic growth/fluctuations. The set-up is a dynamic stochastic general equilibrium model of growth and endogenously chosen fiscal policy, in which two political parties can alternate in power. The party in office chooses jointly how much to tax and how to allocate its total expenditure between public consumption and production services. The main theoretical prediction is that forward-looking incumbents, with uncertain prospects of re-election, find it optimal to follow relatively shortsighted fiscal policies, and that this lowers economic growth. The model is estimated using quarterly data for Germany, the UK and the US from 1960 to 1999 . Our econometric results provide clear support for the main theoretical prediction. They also give plausible and significant estimates for the productivity of public production services, the weight which households place on public consumption services relative to private consumption and the time discount rate. Moreover, we find that changes in electoral uncertainty produce the longest lasting fluctuations in the European economies followed by the US.
\end{abstract}

Keywords: Political uncertainty, economic growth and fluctuations, optimal policy. JEL classification numbers: D9, E6, H1, H5.

Acknowledgements: We would like to thank Fabrizio Carmignani, Francesca Flamini, Tryphon Kollintzas, Campbell Leith, Ben Lockwood and Simon Price for helpful comments and suggestions on earlier versions of this paper. All errors remain our own.

*Corresponding author: Apostolis Philippopoulos, Athens University of Economics and Business, 76 Patission Street, Athens 10434, Greece. Tel: +30-210-8203415. Fax: +30-210-8214122. Email: aphil@aueb.gr. 


\section{Introduction}

Over the past forty years there is mounting evidence in most OECD economies suggesting both secular and cyclical changes in the composition of government expenditure in favor of public consumption at the expense of public investment. ${ }^{1}$ Moreover, several authors (see e.g. Kneller et al. (1999), Alesina (1999) and Tanzi and Schuknecht (2000)) have suggested that these fiscal changes are possible contenders to explain lower than expected economic growth in recent decades. In an effort to provide one possible description of the process leading to the observed fiscal outcomes, we develop a dynamic stochastic general equilibrium model that examines the implications of electoral competition between incumbents and challengers for the choice of fiscal policies and in turn their impacts on aggregate growth and fluctuations.

The literature on elections, fiscal policy and economic growth is rich and still growing (very good surveys can be found in Alesina et al. (1997), Persson and Tabellini (1999) and Drazen (2000)). While there are several channels through which electoral uncertainty can affect policymakers' behavior, ${ }^{2}$ a central result of the theoretical literature is that uncertainty about remaining in office pushes incumbent politicians to follow relatively short-sighted policies and engineer electoral business cycles, which in turn result in inefficient macroeconomic outcomes. ${ }^{3}$ However, the econometric evidence to date is rather mixed. For instance, while there is some evidence of electoral effects on fiscal policy instruments, there is no evidence that this is translated into observed changes in macroeconomic activity (see Alesina et al. (1997, chapters 6 and 7) and Drazen (2000,

\footnotetext{
${ }^{1}$ See e.g. Tanzi and Schuknecht (2000) and the references cited therein.

${ }^{2}$ See e.g. Drazen (2000, pp. 220-2) and Persson and Tabellini (1999, p. 1471) for a survey. More details will follow below.

${ }^{3}$ On the other hand, elections (or the fear of losing them) can work as a disciplinary device (see e.g. Drazen (2000, chapter 7.2)). For instance, they control the moral hazard of politicians, help voters to select the most competent politician, or help voters to select the policymaker whose ideology is closer to their own. Here,
} 
chapters 7.3 and 11.6)). ${ }^{4}$ More importantly, irrespective of the econometric results, there seems to be a gap between the theoretical literature and the final econometric specification. In particular, with few notable exceptions, ${ }^{5}$ econometric estimations are based on simple autoregressive specifications in which various policy instruments and economic outcomes are regressed on lagged values, political dummies (e.g. election and partisan dummies) and measures of sociopolitical instability (e.g. government stability and regime changes). However, to more thoroughly evaluate the implications of electoral competition for economic policy and macroeconomic outcomes, it is important to formally identify the channel(s) through which electoral uncertainty affects policymakers' behavior.

To this end we construct and estimate a dynamic stochastic general equilibrium model of economic growth and endogenously chosen fiscal policy consisting of a private sector and two political parties. The private sector comprises a representative household and a representative firm. The household consumes, works and saves in the form of capital. The firm uses capital and labour to produce a single good. The political parties can alternate in power according to an exogenous stochastic reelection probability. ${ }^{6}$ The party that wins the election forms a government that chooses economic policy during its term in office knowing that it might be out of the power in the future. It also plays noncooperatively (Nash) vis-à-vis the out-of-power party. By economic policy, we mean here

\footnotetext{
following most of the related macroeconomics literature, we abstract from the benefits of electoral competition.

${ }^{4}$ Although there are several explanations for this (see Drazen (2000, pp. 244-6)), our reading of the literature is that this is still an open issue.

${ }^{5}$ Examples of papers which formally estimate theory-based models include: Alesina and Sachs (1988) for a partisan model of monetary policy for the US; Alogoskoufis et al. (1992) for a model of exchange-rate policy for the UK; and Lockwood et al. (1996) for a public-finance model for the UK.

${ }^{6}$ Assuming that re-election probabilities are endogenous (e.g. they depend also on the state of the economy) would not change our main theoretical results. More importantly, the assumption that reelection probabilities are exogenous is deliberate, i.e. we want to examine how electoral uncertainty affects policy choices and the macro-economy. Specifically, we will assume that the stochastic structure of our exogenous election process is first-order Markov. Dixit et al. (2000) assume a similar exogenous political process and provide empirical support. Note that this process reflects that there is persistence to political parties' popularity and competence (the realization of which determine the election outcome) across terms of office (see also e.g. Drazen (2000, p. 270 and p. 276) and Price and Sanders (1994) for the UK).
} 
the income tax rate and the allocation of total tax revenues between public consumption services (which provide direct utility to households) and public production services (which provide production externalities to private firms and hence generate Barro (1990)-type long-term growth). We solve for Markov policy strategies, and hence a Markov-perfect general equilibrium, in which optimal decisions depend on the game's current position. An advantage of our modeling framework is that it allows us to distinguish the effects of electoral uncertainty upon economic policy from its effects upon macroeconomic outcomes in a unified general equilibrium setting. ${ }^{7}$ Another advantage is that it allows us to obtain an explicit analytical solution for the general equilibrium, so that the model is easy to interpret, tractable and useful for formal econometric estimation. ${ }^{8}$

Our main theoretical prediction is as follows. When the expected probability of being re-elected decreases, the total government expenditure-to-output ratio (and the associated tax burden) increases, while the share of tax revenue used to finance public production services decreases. Both fiscal policy instruments work in the same direction, so that - in general equilibrium - a lower re-election probability leads to lower economic growth. Intuitively, when there is electoral uncertainty and the political parties do not care (or care relatively little) about the economy when out of power, they effectively face a quasi-finite time horizon. ${ }^{9} \quad$ The higher the electoral uncertainty (i.e. the smaller the

\footnotetext{
${ }^{7}$ As Drazen (2000, p. 517) points out, it is necessary to estimate jointly the so-called "political" mechanism (the effect of socio-economic variables on the choice of policy instruments) and the so-called "economic" mechanism (the effect of policy instruments on macroeconomic outcomes).

${ }^{8}$ See e.g. Campbell (1994) for the advantages of analytical solutions especially in growth models.

${ }^{9}$ The mechanism is as in Lockwood et al. (1996). See Persson and Tabellini (1999, p. 1471) for a survey of the related literature, namely how electoral uncertainty induces more "myopic" fiscal policies. Economides et al. (2003) have shown that, only if there are extra rents from being in power per se, the parties find it optimal to care relatively more about economic outcomes when in power, and it is this that generates typical electoral cycles. Note that this mechanism is somewhat different from e.g. Rogoff and Sibert (1988) and Rogoff (1990) where the incumbent government manipulates policy instruments in an attempt to increase its re-election probability. It is also distinct from e.g. Persson and Svensson (1989) and Alesina and Tabellini (1990) where the incumbent government uses strategically the state variables (e.g. public debt) to reduce the choices of its successor. For a clear survey, see Drazen (2000, pp. 220-2).
} 
probability of being re-elected), the less they care about the future. As a result, they choose shortsighted, inefficient policies. ${ }^{10}$

In our econometric work, we estimate the general equilibrium model by using quarterly data for Germany, the UK and the US over the period 1960 to 1999 . To this end, we employ constrained maximum likelihood using the Kalman filter. In contrast to the calibration exercises conducted in the RBC literature, estimation of the model's structural parameters not only allows us to assess their individual significance, but also to undertake dynamic inference when conducting the impulse response analysis. Our econometric results provide clear support for the main theoretical proposition. Namely, in all three countries, electoral competition pushes governments to follow short-sighted, inefficient fiscal policies (in the form of a high tax burden and a preference for non-productive activities with short-term benefits) and this is in turn detrimental for the macro-economy.

Our main numerical results are as follows. The productivity of public production services relative to private capital is highest in Germany (0.309) followed by the US ( 0.279$)$ and the UK $(0.270)$. The estimates for the weight given to public consumption services relative to private consumption are $0.385,0.475$ and 0.600 for the US, Germany and the UK respectively. The estimates for the time discount rate are $0.954,0.978$ and 0.986 for the US, Germany and the UK respectively. Finally, persistence of political uncertainty is greatest in the UK (0.961), followed by Germany (0.918) and the US (0.889). The latter finding appears to be in line with business cycle stylised facts, i.e. the US cycle is the shortest followed by Germany and the UK (see, e.g., Zarnowitz (1992) and Woitek (1996)).

\footnotetext{
${ }^{10}$ Svensson (1998) obtains a similar prediction in a model in which political instability pushes rational incumbents to under-invest in legal infrastructure, resulting in weak property rights and low investment.
} 
The rest of the paper is organized as follows. Section 2 presents the theoretical model. Section 3 summarizes the data and the econometric methods employed. Empirical results are presented in Section 4, while Section 5 contains our conclusions. Finally, algebraic details pertaining to the model are gathered in the Appendices.

\section{The Theoretical Model}

In this section, we solve for the optimal decisions of households, firms and political parties. The (Markov-perfect) general equilibrium solution will consist of a system of loglinear dynamic equations, which jointly specify the paths of private consumption, private investment, government consumption and production services, the tax burden and the share of tax revenues allocated to government production relative to government consumption services. That solution will be in terms of the predetermined capital stock and the expected values of exogenous electoral uncertainty. The underlying setup is a two-party variant of Barro's (1990) well-known model of long-term growth and optimally chosen fiscal policy. $^{11}$ The other difference is that here there are also public consumption services so that the incumbent party also chooses the allocation of total tax revenues between production and consumption services. $^{12}$

\subsection{Definition of equilibrium and how we are going to work}

The time horizon is infinite. For simplicity, we assume that elections are held every time period. In each period $t$, the sequence of events is as follows: first, current uncertainty is resolved; in turn, the in-power political party chooses economic policy

\footnotetext{
${ }^{11}$ See also e.g. Barro and Sala-i-Martin (1995, chapter 4) and Glomm and Ravikumar (1994, 1997). Benhabib et al. (2001) focus on the properties of optimal fiscal policy in this model.

${ }^{12}$ See also Park and Philippopoulos $(2003,2004)$ for growth models in which the government chooses the allocation of tax revenues to different activities (e.g. public investment, public consumption and redistributive transfers). However, these models assume a single benevolent government that chooses Ramsey-type optimal open loop policies.
} 
during its term in office; finally, private agents make their allocation decisions. ${ }^{13}$ We will solve the problem by backward induction: within each $t$, we will first solve the private agents' optimization problem for any feasible economic policy; in turn, we will endogenize economic policy by solving the political parties' optimization problem.

We will solve the optimization problems of private agents and political parties by using the method of dynamic programming. The solution will give Markov policy strategies and hence a Markov-perfect general equilibrium. ${ }^{14}$ Thus, optimal policies will be subgame perfect and time consistent. Further, when we form a non-cooperative game between the political parties, the parties' Markov policy strategies will be a Nash equilibrium of that game. ${ }^{15}$

When exact analytical solutions cannot be obtained, we will use first-order Taylor approximations around the non-stochastic long-run values of the relevant exogenous variables. Specifically, this will enable us to obtain approximate closed-form analytical solutions for the value functions in the dynamic programming problems of private agents and political parties. Campbell and Viceira (2002, chapter 5) use a similar type of approximation to solve the Bellman equation in dynamic asset pricing models. ${ }^{16}$ These approximations will hold in expected value - a certainty equivalence property.

\footnotetext{
${ }^{13}$ Thus, all decisions are made after the current uncertainty is resolved, so that all economic agents can choose directly the value of next period's state variables. This makes the solution to the dynamic programming problem simpler, see e.g. Stokey and Lucas (1989, p. 240).

${ }^{14}$ Following Fudenberg and Tirole (1991, pp. 513-5), a Markov perfect equilibrium is defined to be a profile of optimal strategies that are a sub-game perfect equilibrium and depend on the current state of the game only. Specifically, optimal strategies depend only on the set of state variables that are payoff-relevant, i.e. they directly affect the current payoff function. As is known, Markov strategies are without memory.

${ }^{15}$ See also Ljungqvist and Sargent (2000, chapter 6) for examples of what they call "Nash-Markov perfect equilibria". See below for details.

${ }^{16}$ As Campbell and Viceira (2002, chapter 5) explain, this is the same type of approximation used in e.g. Campbell (1993), but instead of using it to linearize the budget constraint, here we use it to solve the Bellman equation. Campbell and Viceira also discuss how various authors have suggested different approximate analytical solutions for the Bellman equation.
} 


\subsection{Behavior of households}

The representative household maximizes intertemporal utility:

$E_{0} \sum_{t=0}^{\infty} \beta^{t} u\left(c_{t}, h_{t}\right)$

where $c_{t}$ and $h_{t}$ are respectively private consumption and public consumption services at time $t, 0<\beta<1$ is the discount rate, and $E_{t}$ denotes the mathematical expectation conditional on information known at $t$. At time $t$, current and past values of all variables are assumed to be known. For simplicity, the utility function $u($.$) is additively separable$ and logarithmic:

$u\left(c_{t}, h_{t}\right)=\log c_{t}+\delta \log h_{t}$

where $0 \leq \delta \leq 1$ is the weight given to public consumption relative to private consumption.

At time $t$, the household rents its predetermined capital, $k_{t}$, to the firm and receives $r_{t} k_{t}$, where $r_{t}$ is the market return to capital. It also supplies inelastically one unit of labor services per time-period so that the labor income is $w_{t}$. Further, it receives profits, $\pi_{t}$. Thus, the household's budget constraint is:

$k_{t+1}+c_{t}=\left(1-\theta_{t}\right)\left(r_{t} k_{t}+w_{t}+\pi_{t}\right)$

where $k_{t+1}$ is the end-of-period capital stock and $0<\theta_{t}<1$ is the income tax rate. For simplicity, we assume full capital depreciation (implying that the end-of-period capital stock is equal to investment). The initial capital stock, $k_{0}$, is given.

The household acts competitively by taking prices, tax policy and public services as given. From the household's viewpoint, the state variables at time $t$ are the predetermined capital stock, $k_{t}$, and current economic policy. As is shown below, the independent economic policy instruments at any $t$ are the income tax rate, $\theta_{t}$, and the share of total tax 
revenue used to finance public production services, $b_{t}$. Therefore, let $V\left(k_{t} ; \theta_{t}, b_{t}\right)$ denote the value function of the household at any $t .{ }^{17}$ This function satisfies the Bellman equation:

$$
V\left(k_{t} ; \theta_{t}, b_{t}\right)=\max _{c_{t}, k_{t+1}}\left[\log c_{t}+\delta \log h_{t}+\beta E_{t} V\left(k_{t+1} ; \theta_{t+1}, b_{t+1}\right)\right] .
$$

Using (2) for $c_{t}$ into (3), the first-order condition for $k_{t+1}$ and the envelope condition for $k_{t}$ are respectively: ${ }^{18}$

$$
\begin{aligned}
& \frac{1}{c_{t}}=\beta E_{t} V_{k}\left(k_{t+1} ; \theta_{t+1}, b_{t+1}\right) \\
& V_{k}\left(k_{t} ; \theta_{t}, b_{t}\right)=\frac{\left(1-\theta_{t}\right) r_{t}}{c_{t}} .
\end{aligned}
$$

\subsection{Behavior of firms}

As in the literature introduced by Barro (1990), we assume that public services provide production externalities to private firms. We also assume that technology at the firm's level takes a Cobb-Douglas form. ${ }^{19}$ Thus, the production function of the representative firm is:

$$
y_{t}=A k_{t}^{\alpha} l_{t}^{1-\alpha} g_{t}^{1-\alpha}
$$

where $l_{t}$ is the labor input at $t, g_{t}$ is public production services at $t, A>0$ and $0<\alpha<1$

(we assume that aggregate productivity, $A$, is constant so as to focus on growth and fluctuations driven by electoral uncertainty).

${ }_{17}$ As is known, with logarithmic preferences, Cobb-Douglas constraints and full depreciation, explicit
closed-form solutions for the optimal controls, $c_{t}$ and $k_{t+1}$, can be easily obtained by assuming that controls
are time-invariant functions of the current state and using these conjectures into the Euler equation (see e.g.
McCallum (1989, pp. 21-22)). Here, we choose to use dynamic programming to cope with any possible
complications arising from the presence of the exogenous (from the viewpoint of private agents) stochastic
policy instruments, $\theta_{t}$ and $b_{t}$. It is easy to show that the solutions for $c_{t}$ and $k_{t+1}$ (see (10a)-(10b) below)
are the same independently of the solution technique. On the other hand, here we also obtain an approximate
solution for the value function in (3) (details will be given in Appendix A). ${ }^{18}$ Equations (4a)-(4b) combined give the familiar Euler equation, $\frac{1}{c_{t}}=\beta E_{t}\left[\frac{\left(1-\theta_{t+1}\right) r_{t+1}}{c_{t+1}}\right]$. 
The firm maximizes profits, $\pi_{t}$, given by:

$\pi_{t} \equiv y_{t}-r_{t} k_{t}-w_{t} l_{t}$

The firm also acts competitively by taking prices and public services as given. The

first-order conditions, that also imply zero profits, are simply:

$$
\begin{aligned}
& r_{t}=\frac{\alpha y_{t}}{k_{t}} \\
& w_{t}=\frac{(1-\alpha) y_{t}}{l_{t}} .
\end{aligned}
$$

\subsection{Government budget constraint}

At each time $t$, the government runs a balanced budget by taxing the household's income at a rate $0<\theta_{t}<1 .^{20}$ Thus,

$h_{t}+g_{t}=\theta_{t}\left(r_{t} k_{t}+w_{t}+\pi_{t}\right)$.

Without loss of generality, we assume that a share $0<b_{t}<1$ of total tax revenues finances public production services, $g_{t}$, and the rest $0<\left(1-b_{t}\right)<1$ finances public consumption services, $h_{t}$. Thus, (8a) is decomposed into:

$$
\begin{aligned}
& g_{t}=b_{t} \theta_{t}\left(r_{t} k_{t}+w_{t}+\pi_{t}\right) \\
& h_{t}=\left(1-b_{t}\right) \theta_{t}\left(r_{t} k_{t}+w_{t}+\pi_{t}\right)
\end{aligned}
$$

where inspection of (8a)-(8c) reveals that $\theta_{t}$ and $b_{t}$ can summarize fiscal policy at $t$.

\footnotetext{
${ }^{19}$ The firm is modeled as in Barro and Sala-i-Martin (1995, chapter 4).

${ }^{20}$ For simplicity, there is no public debt in the model since adding one more state variable would not change our main results (see e.g. Devereux and Wen (1998) who employ a similar setup). RBC papers that also omit public debt include Baxter and King (1993), McGrattan (1994), Ambler and Paquet (1996) and Klein, Quadrini and Rios-Rull (2003). Finally note that in a public finance model including debt, Lockwood et al. (1996) have shown that short-sighted fiscal policies - driven by electoral uncertainty - are also reflected into over-accumulation of public debt.
} 


\subsection{Competitive decentralized equilibrium (for given economic policy)}

Given the time-path of economic policy $\left\{\theta_{t}, b_{t}\right\}_{t=0}^{\infty}$, a competitive decentralized equilibrium (CDE) is defined to be a sequence of allocations $\left\{k_{t+1}, c_{t}, h_{t}, g_{t}\right\}_{t=0}^{\infty}$ and prices $\left\{r_{t}, w_{t}\right\}_{t=0}^{\infty}$ such that: (i) households maximize utility and firms maximize profits by taking prices, policy and public services as given; (ii) all budget constraints are satisfied; (iii) all markets clear. $^{21}$ This CDE is described by equations (1)-(8) above. The rest of this subsection will take advantage of the specific functional forms used to obtain a convenient closed-form solution for the CDE.

Consider the economy-wide output. Using (7a), (7b) and (8b) into (5), we find:

$$
y_{t}=r_{t} k_{t}+w_{t}+\pi_{t}=A^{\frac{1}{\alpha}}\left(b_{t} \theta_{t}\right)^{\frac{1-\alpha}{\alpha}} k_{t}
$$

which shows that the model is a variant of the linear $A K$ model. As in e.g. Barro (1990), the coefficient " $A$ " is a function of policy instruments. ${ }^{22}$

$$
\text { Then, Appendix A shows: }{ }^{23}
$$

Result 1: In a competitive decentralized equilibrium (for any feasible Markov economic policy), optimal private consumption and capital accumulation are:

$$
\begin{aligned}
& c_{t}=(1-\alpha \beta) A^{\frac{1}{\alpha}}\left(1-\theta_{t}\right)\left(b_{t} \theta_{t}\right)^{\frac{1-\alpha}{\alpha}} k_{t} \\
& k_{t+1}=\alpha \beta A^{\frac{1}{\alpha}}\left(1-\theta_{t}\right)\left(b_{t} \theta_{t}\right)^{\frac{1-\alpha}{\alpha}} k_{t} .
\end{aligned}
$$

\footnotetext{
${ }^{21}$ In the labor market, the market-clearing condition is $l_{t}=1$.

${ }^{22}$ Using (9) into (7a), we obtain $r_{t}=\alpha A^{\frac{1}{\alpha}}\left(b_{t} \theta_{t}\right)^{\frac{1-\alpha}{\alpha}}$, which is the return to capital that drives private
} decisions. On the other hand, (9) implies that the social return to capital is $\frac{\partial y_{t}}{\partial k_{t}}=A^{\frac{1}{\alpha}}\left(b_{t} \theta_{t}\right)^{\frac{1-\alpha}{\alpha}}$. Since $0<\alpha<1$, the social return to capital exceeds the perceived or private return. Thus, under production externalities, the decentralized growth rate is inefficiently low.

${ }^{23}$ As Appendix A shows, by taking first-order Taylor approximations around the long-run values of the exogenous variables, $\theta_{t}$ and $b_{t}$, we can also obtain an approximate solution for the value function in (3). 
It is also useful for what we do next, to write the solutions for the two types of public services, $g_{t}$ and $h_{t}$, in a CDE. Using (9), (8b) and (8c) become respectively:

$$
\begin{aligned}
& g_{t}=\left(A b_{t} \theta_{t}\right)^{\frac{1}{\alpha}} k_{t} \\
& h_{t}=\left(1-b_{t}\right) b_{t}^{\frac{1-\alpha}{\alpha}} A^{\frac{1}{\alpha}} \theta_{t}^{\frac{1}{\alpha}} k_{t} .
\end{aligned}
$$

To summarize results so far, equations (10a), (10b), (10c) and (10d) give $c_{t}, k_{t+1}$, $g_{t}$ and $h_{t}$ respectively in a CDE. This is a function of the predetermined capital stock, $k_{t}$, and the current policy instruments, $\theta_{t}$ and $b_{t}$, only. The next subsection will endogenize the choice of $\theta_{t}$ and $b_{t}{ }^{24}$

Before we move on to choose economic policy, notice two features of the CDE. First, (10b) implies that the sign of $\frac{\partial_{t+1}}{\partial \theta_{t}}$ is the sign of $\left(1-\alpha-\theta_{t}\right)$. If $\left(1-\alpha-\theta_{t}\right)>0, k_{t+1}$ increases with $\theta_{t}$; if $\left(1-\alpha-\theta_{t}\right)<0, k_{t+1}$ decreases with $\theta_{t}$. Thus, the effect of the tax rate on the growth rate is an inverse U-curve, as in Barro (1990). ${ }^{25}$ Second, (10b) implies $\frac{\partial k_{t+1}}{\partial b_{t}}>0$. Thus, a higher share of tax revenues used to finance public production services relative to public consumption services stimulates ceteris paribus economic growth monotonically.

\footnotetext{
${ }^{24}$ Here we do not model voting behavior. We also assume that private agents are indifferent over which party wins the election (this is not restrictive because we will solve for symmetric equilibria). All this means that elections can affect the CDE only indirectly via the choice of economic policy, $\theta_{t}$ and $b_{t}$. This is deliberate since our focus is on the implications of electoral uncertainty. For voting behavior, see e.g. Persson and Tabellini (2000, chapter 4.5).

${ }^{25}$ Intuitively, when the tax rate is initially low, any marginal increase will lead to higher tax revenues and higher public production services which increase the productivity of private capital; this more than offsets the distortionary effect of higher taxation. The opposite happens when the tax rate is initially high.
} 
To endogenize economic policy, we form a non-cooperative (Nash) game between two political parties, denoted by $i$ and $j$, which alternate in power according to an exogenous stochastic reelection probability. ${ }^{26}$ Specifically, if elections take place in each time-period, we assume that the party in power at $t$ has a probability $0 \leq q_{t+1} \leq 1$ of winning the next election and remaining in power at $t+1$, and a probability $\left(1-q_{t+1}\right)$ of losing the election and being out of power at $t+1$. In other words, $q_{t+1}$ denotes the probability that the incumbent wins the election.

To specify the motion of $q_{t+1}$ we assume that it follows an exogenous first order autoregressive process. Thus,

$q_{t+1}=q_{0}+\rho q_{t}+\varepsilon_{t+1}$

where $q_{0}>0$ is a constant, $0<\rho<1$ is the autoregressive parameter, $\varepsilon_{t}$ is $\operatorname{IID}\left(0, \sigma^{2}\right)$ and $0 \leq q_{t} \leq 1$ for all $t .{ }^{27}$ That is, $q_{t}$ is a non-negative stochastic variable that is bounded from above with probability 1 .

Given the above, a political general equilibrium is defined as follows: (i) The elected party $i$ chooses $\theta_{t}$ and $b_{t}$ to maximize the utility of the representative household

\footnotetext{
${ }^{26}$ Assuming that re-election probabilities depend also on the state of the economy would not change our main theoretical results. For instance, assume that the reelection probability is a positive function of recent economic growth. This would give an incentive to the incumbent party to follow more long-sighted policies (so as to stimulate growth and increase its chances of reelection) than in the case in which the reelection probability is exogenous. However, it would still be the case that, since the reelection probability is less than one, policies are less long-sighted than in the case without electoral uncertainty.

${ }^{27}$ We include a constant, $q_{0}>0$, since otherwise the mean of $q_{t}$ would be zero, which is counter intuitive in the case of reelection probabilities given that electoral uncertainty is always present. Also note that the autoregressive process we have chosen is consistent with previous empirical studies. For instance, when Price and Sanders (1994) examine the determinants of government popularity in post-war Britain, they find evidence of substantial history-dependence in popularity. Finally, note that while the theoretical model can be solved using higher order processes for $q$, we find in our econometric estimation below that only first order terms are significant. To preserve space, these results are not reported here but will be made available upon request.
} 
in (1a)-(1b) subject to the CDE summarized by (10a)-(10d), and by taking as given the policy of the other party, $j \neq i$, which may be in power at $t+1$. That is, the in-power party plays Nash vis-a-vis the out-of-power party. The out-of-power party takes no action until it wins an election. (ii) We solve for Markov policy strategies, i.e. $\theta_{t}$ and $b_{t}$ can be functions of the current state of the game. (iii) We solve for a symmetric Nash equilibrium in Markov policy strategies, i.e. parties' policies will be symmetric ex post. $^{28}$ (iv) We assume that political parties do not care about the economy when out of power. Implicit here is the assumption that they earn extra rents when in power. ${ }^{29}$ (v) The solution for $\theta_{t}$ and $b_{t}$, in combination with the $\mathrm{CDE}$ above, will give a Markov-perfect political general equilibrium.

\subsection{Problem formulation and chosen fiscal policies}

Recall that all current and past values are known at the beginning of $t$. Then, from the political parties' viewpoint, the state variables at $t$ are the economy's inherited capital stock $k_{t}$, and the current value of the exogenous $A R(1)$ shock, $q_{t} \cdot{ }^{30}$ Therefore, let $V^{P_{i}}\left(k_{t} ; q_{t}\right)$ and $V^{N_{i}}\left(k_{t} ; q_{t}\right)$ denote the value functions of party $i$ at time $t$ when in power and when out of power respectively (party $j$ 's problem is symmetric). These value functions must satisfy the following pair of Bellman equations: ${ }^{31}$

$$
V^{P_{i}}\left(k_{t} ; q_{t}\right)=\max _{\theta_{t}^{i}, b_{t}^{i}}\left\lfloor\log c_{t}+\delta \log h_{t}+\beta E_{t}\left\lfloor q_{t+1} V^{P_{i}}\left(k_{t+1} ; q_{t+1}\right)+\left(1-q_{t+1}\right) V^{N_{i}}\left(k_{t+1} ; q_{t+1}\right)\right\rfloor\right.
$$

\footnotetext{
${ }^{28}$ Thus, there are no partisan effects. Here, the focus is on the effects of electoral uncertainty. Note that partisan effects do not have a persistent impact on growth [for evidence, see e.g. Alesina et al. (1997)].

${ }^{29}$ This is for simplicity. Our results do not change if we assume that parties care less about the economy when out of power than when in power. See Economides et al. (2003) for the micro-economic determinants of these political preferences in a similar setup. See also Lockwood et al. (1996) for references from the political science literature that support this approach.

${ }^{30}$ Since $k_{t}$ and $q_{t}$ are the payoff-relevant state variables, this selection of state variables is consistent with the definition of Markov strategies (see also Appendix B).

${ }^{31}$ See Alesina and Tabellini (1990) and Lockwood et al. (1996) for a similar approach.
} 
$V^{N_{i}}\left(k_{t} ; q_{t}\right)=\left\lfloor 0+\beta E_{t}\left\lfloor\left(1-q_{t+1}\right) V^{P_{i}}\left(k_{t+1} ; q_{t+1}\right)+q_{t+1} V^{N_{i}}\left(k_{t+1} ; q_{t+1}\right)\right\rfloor\right.$

where $c_{t}, k_{t+1}$ and $h_{t}$ follow (10a), (10b) and (10d) respectively. Notice that in (12a), the incumbent has a probability $q_{t+1}$ of remaining in power, and a probability $\left(1-q_{t+1}\right)$ of losing the coming election. In (12b), the party out of power knows that there is a probability $q_{t+1}$ of continuing to be out of power and a probability $\left(1-q_{t+1}\right)$ of coming back to power in the next election. When out of power, parties do not care about macro outcomes; hence the zero term on the right hand side of (12b). In (12a), all policy instruments are chosen by the incumbent party $i$, while in (12b) all policy instruments are those of party $j$ since party $i$ is out of power. ${ }^{32}$ Finally, notice that the optimization problem in $(12 a)-(12 b)$ has a recursive structure. ${ }^{33}$

Then, Appendix B shows: ${ }^{34}$

Result 2: In a Markov-perfect general equilibrium of a symmetric Nash game between the political parties, the income tax rate, $\theta_{t}$, and the share of total tax revenues used to finance public production services, $b_{t}$, are equal to:

$$
\begin{aligned}
& 1-\alpha<\theta_{t}=\frac{\delta+(1-\alpha) E_{t} \Omega_{t+1}}{\delta+E_{t} \Omega_{t+1}}<1 \\
& 1-\alpha<b_{t}=\frac{(1-\alpha)\left(\delta+E_{t} \Omega_{t+1}\right)}{\delta+(1-\alpha) E_{t} \Omega_{t+1}}<1
\end{aligned}
$$

${ }^{32}$ That is, in (12a) $k_{t+1}=\alpha \beta A^{\frac{1}{\alpha}}\left(1-\theta_{t}^{i}\right)\left(b_{t}^{i} \theta_{t}^{i}\right)^{\frac{1-\alpha}{\alpha}} k_{t}$ because party $i$ has been in power at $t$, while in (12b) $k_{t+1}=\alpha \beta A^{\frac{1}{\alpha}}\left(1-\theta_{t}^{j}\right)\left(b_{t}^{j} \theta_{t}^{j}\right)^{\frac{1-\alpha}{\alpha}} k_{t}$ because party $j$ has been in power at $t$.

${ }^{33}$ It is recursive in the sense that, given the other party's policy choices, current policy choices affect returns dated $t$ and later but not earlier (see Sargent (1987)). In a recursive formulation, optimal policies are time consistent (see also Ljungqvist and Sargent (2000)).

${ }^{34}$ As before, to obtain closed-form analytical solutions for the value functions defined in (12a)-(12b), we use first-order Taylor approximations around the long-run value of the exogenous variable, $q_{t}$. See Appendix B for details. 
where, $E_{t} \Omega_{t+1}=\frac{(1+\delta)\left(1-\beta E_{t} q_{t+1}\right)}{(1-\beta)\left(1+\beta-2 \beta E_{t} q_{t+1}\right)}-\delta>0$ and $E_{t} q_{t+1}=q_{0}+\rho q_{t}$ from (11). Thus, the solution has the certainty equivalence property in the sense that it holds in expected value. $^{35}$

In what follows, we focus on the effects of electoral uncertainty, as summarized by the expected re-election probability, $E_{t} q_{t+1}$. The expected "effective discount rate", defined as $E_{t} \Omega_{t+1}$, increases with $E_{t} q_{t+1}$. In other words, as the probability of being reelected increases, policymakers care effectively more about the future. In turn, (13a) and (13b) imply $\frac{\partial \theta_{t}}{\partial E q_{t+1}}<0$ and $\frac{\partial b_{t}}{\partial E_{t} q_{t+1}}>0$. In other words, as the probability of being reelected increases, the total government expenditures-to-output ratio (and the associated required tax rate, $\left.\theta_{t}\right)^{36}$ decreases, while the share of tax revenues earmarked for financing government production services, $b_{t}$, increases. Then, since $\frac{k_{t+1}}{k_{t}}=\alpha \beta A^{\frac{1}{\alpha}}\left(1-\theta_{t}\right)\left(b_{t} \theta_{t}\right)^{\frac{1-\alpha}{\alpha}}$ is decreasing in $\theta_{t}$ and increasing in $b_{t}$ along the optimal path, ${ }^{37}$ it follows that, as $q_{t+1}$

\footnotetext{
${ }^{35}$ Notice three features of the solution in (13a)-(13b). First, if $q_{t}$ is constant, it is optimal to keep the policy instruments flat over time. This is as in the basic Barro (1990) setup, in which the optimal open loop tax rate that maximizes the utility of the representative agent (or equivalently the growth rate) is flat over time and there is no time inconsistency problem (for details, see Benhabib et al. (2001)). Second, $\theta_{t}>(1-\alpha)$, where $(1-\alpha)$ is the productivity of public services. By contrast, $\theta_{t} \equiv \theta=(1-\alpha)$ in Barro (1990). This is because here there are also public consumption services and electoral competition; both lead to larger public sectors and higher tax rates. Third, the two policy instruments, $\theta_{t}$ and $b_{t}$, should move in opposite direction in each period. Intuitively, when the government allocates a larger share of tax revenues to public production services (i.e. $b_{t}$ increases), it can afford a lower tax rate (i.e. $\theta_{t}$ decreases) since public production services stimulate private investment and hence increase the tax base. Thus, $\theta_{t}$ and $b_{t}$ are substitutes along the optimal path (see also Park and Philippopoulos (2003)).

${ }^{36}$ This follows from (8a), where $\frac{g_{t}+h_{t}}{y_{t}}=\theta_{t}$.

37 Since $\left(1-\alpha-\theta_{t}\right)<0$ along the optimal path, it follows from (10b) that $k_{t+1}$ decreases with $\theta_{t}$. Intuitively, when policy is chosen endogenously, it is not possible for any further increases in tax policy actions to be welfare increasing (compare it with (10b) above where policy was exogenous).
} 
increases, both policy instruments work in the same direction leading to an increase in capital and output growth.

The intuition is as follows. When there is electoral uncertainty (in the sense that there is a non-zero probability of being out of power in the next election), and the political parties care less about economic outcomes when out of power than when in power, they face a quasi-finite time horizon (see also Lockwood et al. (1996)). As a result, the party in power, which is the party that sets policy, cares effectively less about the future. Specifically, the higher the electoral uncertainty (i.e. the smaller the probability of being re-elected), the less it cares about the future. In our model, higher electoral uncertainty pushes policymakers to go for a higher total expenditures-to-output ratio and also spend more on non-productive activities relative to productive activities. Here, the benchmark case is the second-best case without any electoral uncertainty, $q_{t+1}=1$. In turn, the effects of these two policy instruments work in the same direction and discourage private capital accumulation and economic growth. We summarize results in the following proposition:

Proposition 1: There is a unique Markov-perfect general equilibrium in symmetric Nash strategies among political parties. In this equilibrium, when the probability of being reelected decreases, it is optimal for incumbent politicians to follow relatively shortsighted fiscal policies (in the form of relatively high total expenditure-to-output ratio and low share of tax revenues used to finance government production services) and this is detrimental for economic growth.

\section{The Econometric Model}

In this section we jointly estimate the general equilibrium (GE) model given the exogenous process for $q_{t}$ developed in Section 2 for Germany, the UK and the US using quarterly data from 1960 to 1999 . The GE model consists of equations (10a-10d) and (13a-13b) which gives respectively closed-form solutions for $c_{t}, k_{t+1}, g_{t}, h_{t}, \theta_{t}, b_{t}$. The 
exogenous process for $q_{t}$ is given by equation (11). The internal and external dynamics of the model are captured respectively by the capital stock, $k_{t}$, and the reelection probability, $q_{t}$. To focus attention on the effects that political uncertainty has on policy outcomes and in turn the aggregate economy, we have only specified one explicit stochastic process, namely $q_{t}$. When moving to the econometric specification, we have to account for the fact that our data measures for $q_{t}$ are at best proxies. This is because actual $q_{t}$ embodies multiple dimensions of electoral certainty and political stability in general, which make it different from the $q_{t}$ implied by the model (i.e. the "probability of staying in office"). The remaining deterministic equations of the system are made stochastic by the introduction of measurement errors. ${ }^{38}$

Given that the model in (10a-10d) and (13a-13b) is non-linear, both in variables and parameters, prior to estimation, we transform it into its log-deviations form by using the long-run restrictions imposed by the theory developed in Section 2. This has two advantages: (i) the transformed model is in a form more tractable for estimation, i.e. it becomes log-linear (with the non-linearity only entering in the parameters); (ii) the loglinear structure is necessary when using the Kalman Filter. The latter procedure is a natural choice for this exercise since, as mentioned above, we need to account for both measurement errors and an unobservable component of $q_{t}$.

\footnotetext{
${ }^{38}$ This treatment is particularly relevant when it comes to the distinction between government consumption and production services, $h_{t}$ and $g_{t}$. Typically, national income accounting practice fails to recognise the investment characteristics of many categories of government expenditure. Examples include expenditure on education, or expenditure on social security programs. This is widely recognized in the literature (see e.g. Devarajan et al. (1996) and Gemmell and Kneller (2001)).
} 


\subsection{The Data}

The quarterly time series for private and public consumption and investment are from the OECD Business sector database. As mentioned above, since it is not possible to measure the probability of staying in office directly, we have to use proxies for $q_{t}$. In the case of the UK and Germany, the political data are from the data-set collected by Carmignani (2003). Since we do not have a direct measure for the probability of staying in office, we convert the information from Carmignani's measures for political uncertainty to an index varying between 0 and 1, e.g. $q_{t}=\exp \left(\widetilde{q}_{t}\right) /\left(1+\exp \left(\widetilde{q}_{t}\right)\right)$. Our choice of measures is based on data availability: for Germany, we use an index of portfolio volatility and ideological diversity of the cabinet; for the UK, we use the share of parliamentary support. Portfolio volatility measures the number of changes in the structure of portfolio allocation between two consecutive cabinets. The lower the portfolio volatility, the higher the probability a minister stays in office. Ideological diversity reflects the potential conflict of interest between coalition partners, based on the ideological location of the parties involved in the coalition on a ten points Left-Right continuum (see Carmignani (2003) and the reference cited therein for details). The more diverse the coalition, the smaller is the probability of staying in office. In the case of the UK, and since the UK is a typical singleparty majority system, we cannot use measures based on potential conflicts within a coalition. Instead, we will use the share of parliamentary support (share of seats controlled by the government) as a proxy for the survival probability. In the case of the US, we have (relatively more direct) data on the presidential job approval for the entire observation period collected by the Gallup Organization, ${ }^{39}$ which we convert from the bi-weekly to the quarterly frequency.

\footnotetext{
${ }^{39}$ Source: http://roperweb.ropercenter.uconn.edu/. We are aware that similar data exist for the UK and Germany, but using this would restrict the sample size considerably. For example, in the case of Germany, published opinion poll series do not start before 1977.
} 


\subsection{The Model in log-deviations form}

Taking logs in (10a-10d), (13a-13b) and (11) and differentiating with respect to time (where derivatives are evaluated at long-run values), we obtain (for any variable $x$, $\hat{x}_{t} \equiv \frac{\dot{x}_{t}}{\bar{x}}$, where $\dot{x_{t}} \cong x_{t}-x_{t-1}$ and $\bar{x}$ is the non-stochastic long-run value of $x_{t}$ ):

$\hat{c}_{t}=\frac{(1-\alpha-\bar{\theta})}{\alpha(1-\bar{\theta})} \hat{\theta}_{t}+\frac{(1-\alpha)}{\alpha} \hat{b}_{t}+\hat{k}_{t}$

$\hat{k}_{t+1}=\frac{(1-\alpha-\bar{\theta})}{\alpha(1-\bar{\theta})} \hat{\theta}_{t}+\frac{(1-\alpha)}{\alpha} \hat{b}_{t}+\hat{k}_{t}$

$\hat{g}_{t}=\frac{1}{\alpha} \hat{b}_{t}+\frac{1}{\alpha} \hat{\theta}_{t}+\hat{k}_{t}$

$\hat{h}_{t}=\left(\frac{(1-\alpha-\bar{b})}{\alpha(1-\bar{b})}\right) \hat{b}_{t}+\left(\frac{1}{\alpha}\right) \hat{\theta}_{t}+\hat{k}_{t}$

$\hat{\theta}_{t}=\frac{-\alpha \delta}{(\delta+\bar{\Omega})[\delta+(1-\alpha) \bar{\Omega}]}\left(\frac{\partial \bar{\Omega}}{\partial \bar{q}} \bar{q}\right) \hat{q}_{t+1}$

$\hat{b}_{t}=\frac{\alpha \delta}{(\delta+\bar{\Omega})[\delta+(1-\alpha) \bar{\Omega}]}\left(\frac{\partial \bar{\Omega}}{\partial \bar{q}} \bar{q}\right) \hat{q}_{t+1}$

$\hat{q}_{t+1}=\rho \hat{q}_{t}+\frac{1}{\bar{q}} \dot{\varepsilon}_{t+1}$

where $\bar{\theta}=\frac{\delta+(1-\alpha) \bar{\Omega}}{\delta+\bar{\Omega}}, \bar{b}=\frac{(1-\alpha)(\delta+\bar{\Omega})}{\delta+(1-\alpha) \bar{\Omega}}, \bar{\Omega}=\frac{(1+\delta)(1-\beta \bar{q})}{(1-\beta)(1+\beta-2 \beta \bar{q})}-\delta$,

$\frac{\partial \bar{\Omega}}{\partial \bar{q}}=\frac{(1+\delta) \beta}{(1+\beta-2 \beta \bar{q})^{2}},(\bar{c}, \bar{k}, \bar{g}, \bar{h})$ are deterministic quadratic trends of $(c, k, g, h)$ from the actual data and $\bar{q}=0.5 .^{40}$

${ }^{40}$ The value of $\bar{q}=0.5$ reflects that it is not reasonable to expect either an incumbency advantage or disadvantage in the steady state. 


\subsection{The Kalman Filter set-up}

To estimate the parameters, we first cast the model in equations (14a) - (14g) in state space form. The transition equation system is given by the economic model and determines the dynamics of the $(7 \times 1)$ state vector $\mathbf{a}_{t}$ :

$$
\mathbf{a}_{t}=\mathbf{T} \mathbf{a}_{t-1}+\mathbf{R} \hat{\varepsilon}_{t+2}
$$

with

$$
\mathbf{a}_{t}=\left(\begin{array}{c}
\hat{c}_{t}^{*} \\
\hat{k}_{t+1}^{*} \\
\hat{g}_{t}^{*} \\
\hat{h}_{t}^{*} \\
\hat{\theta}_{t}^{*} \\
\hat{b}_{t}^{*} \\
\hat{q}_{t+2}^{*}
\end{array}\right) ; \mathbf{T}=\left(\begin{array}{ccccccc}
0 & 1 & 0 & 0 & \tilde{a} & \tilde{b} & 0 \\
0 & 1 & 0 & 0 & \tilde{a} & \tilde{b} & 0 \\
0 & 1 & 0 & 0 & \tilde{c} & \tilde{c} & 0 \\
0 & 1 & 0 & 0 & \tilde{c} & \tilde{d} & 0 \\
0 & 0 & 0 & 0 & 0 & 0 & -\tilde{e} \\
0 & 0 & 0 & 0 & 0 & 0 & \tilde{e} \\
0 & 0 & 0 & 0 & 0 & 0 & \rho
\end{array}\right), \mathbf{R}=\left(\begin{array}{c}
0 \\
0 \\
0 \\
0 \\
0 \\
0 \\
1
\end{array}\right),
$$

where,

$$
\begin{aligned}
& \tilde{a} \equiv \frac{(1-\alpha-\bar{\theta})}{\alpha(1-\bar{\theta})} ; \tilde{b} \equiv \frac{(1-\alpha)}{\alpha} ; \tilde{c} \equiv \frac{1}{\alpha} ; \tilde{d} \equiv \frac{(1-\alpha-\bar{b})}{\alpha(1-\bar{b})} ; \tilde{e}=\left(\frac{-\alpha \delta}{(\delta+\bar{\Omega})[\delta+(1-\alpha) \bar{\Omega}]}\right)\left(\frac{(1+\delta) \beta}{(1+\beta-2 \bar{\beta} q)^{2}} \bar{q}\right) \\
& \bar{\theta} \equiv \frac{\delta+(1-\alpha) \bar{\Omega}}{\delta+\bar{\Omega}}, \bar{b} \equiv \frac{(1-\alpha)(\delta+\bar{\Omega})}{\delta+(1-\alpha) \bar{\Omega}}, \bar{\Omega} \equiv \frac{(1+\delta)(1-\beta \bar{q})}{(1-\beta)(1+\beta-2 \beta \bar{q})}-\delta, \text { and } \hat{\varepsilon}_{t} \sim N\left(0, \sigma_{\hat{\varepsilon}}^{2}\right) .
\end{aligned}
$$

In the measurement equation, the state vector is linked to observable $\hat{c}_{t}, \hat{k}_{t+1}, \hat{g}_{t}, \hat{h}_{t}$, and $\hat{q}_{t+2}$ :

$$
\mathbf{y}_{t}=\mathbf{Z} \mathbf{a}_{t}+\boldsymbol{\varepsilon}_{t}
$$

where 


$$
\mathbf{y}_{t}=\left(\begin{array}{c}
\hat{c}_{t} \\
\hat{k}_{t+1} \\
\hat{g}_{t} \\
\hat{h}_{t} \\
\hat{q}_{t+2}
\end{array}\right) ; \mathbf{Z}=\left(\begin{array}{ccccccc}
1 & 0 & 0 & 0 & 0 & 0 & 0 \\
0 & 1 & 0 & 0 & 0 & 0 & 0 \\
0 & 0 & 1 & 0 & 0 & 0 & 0 \\
0 & 0 & 0 & 1 & 0 & 0 & 0 \\
0 & 0 & 0 & 0 & 0 & 0 & 1
\end{array}\right) ; \boldsymbol{\varepsilon}_{t}=\left(\begin{array}{c}
\varepsilon_{1 t} \\
\varepsilon_{2 t+1} \\
\varepsilon_{3 t} \\
\varepsilon_{4 t} \\
\varepsilon_{5 t+2}
\end{array}\right),
$$

$\varepsilon_{t} \sim \mathrm{N}(\mathbf{0}, \mathbf{H})$, and the variance-covariance matrix $\mathbf{H}$ is assumed to be diagonal. We do not require proxies for $\hat{\theta}_{t}$ and $\hat{b}_{t}$, since they can be linked via the $\hat{c}_{t}$ and $\hat{k}_{t+1}$ equations to observable data. The error vector reflects the fact that all variables in the system are subject to measurement error, or have to be seen as proxies, as in the case of $\hat{q}_{t+2}$.

\subsection{Constrained Maximum Likelihood}

Given that the parameters (i.e. $\tilde{a}, \tilde{b}, \tilde{c}, \tilde{d}, \tilde{e})$ are comprised of complex non-linear convolutions of the underlying "deep" parameters $(\alpha, \beta, \delta, \rho)$, which also embody the within- and cross-equation restrictions imposed by the theory, we find it appropriate to employ constrained maximum likelihood estimation. Maximizing the likelihood function using standard numerical methods in these circumstances does not guarantee that the estimated parameters will lie within the ranges suggested by the theory. To ensure this, we could use parameter transformations such as $b=\exp (a) /(1+\exp (a))$ which ensures that $b$ lies in $[0,1]$ interval. However transformations such as these lead to problems with convergence (see Schoenberg (1997)). Accordingly, we will restrict the structural parameters $\alpha, \beta$ and $\delta$ to stay within acceptable ranges (see below).

Before we move on, it is important to point out that, in contrast to standard calibration exercises, our proposed methodology has several advantages. First, we are able to assess the individual statistical significance of each of the structural parameters. Second, when performing the impulse response analysis to ascertain the transition 
dynamics and long-run effects of changes in political uncertainty, we are able to undertake dynamic inference.

To estimate the state space model given by (15) and (16), we calculate the likelihood function using the Kalman filter. As discussed above, when maximising the likelihood, we take into account that all of the variables (with the exception of $\rho$ ) are bounded. The restricted ranges we use are as follows: $\alpha$ (i.e. the productivity of private capital relative to public production services) is in between 0.6 and $0.8, \beta$ (i.e. the time discount rate) lies in between 0.95 and 0.99 , and $\delta$ (i.e. the weight given to public consumption services relative to private consumption) cannot be greater than 1 or less than $0 .^{41}$

The range for $\alpha$ was motivated by Barro and Sala-i-Martin (1995, see e.g. pp 8287), who undertake calibrations using a point estimate of $\alpha=0.75$ for private capital. They argue that a value around 0.75 (which is higher than the one usually used) gives reasonable transitional dynamics, generates predictions that accord well with historical growth experiences in advanced economies and is consistent with a broad measure of private capital. The range for $\beta$ reflects values most often used in the theoretical DSGE literature (see, e.g. Baier and Glomm (2001) and Lansing (1998) who set $\beta$ to 0.98 and 0.96 for the US respectively). Finally, concerning the range for $\delta$, since as Baier and Glomm (2001) state, "little is known about this value", we employ the 0 to 1 range. Note that values of $\delta$ used in calibration studies for the US include 0.287 (see Lansing (1998)), 0.368 (see Guo and Lansing (1999)), 0.107 (see Ambler and Paquet (1996)), while Baier and Glomm (op cit) experiment with values of $(0.15,0.0075,0)$.

\footnotetext{
${ }^{41}$ The variances are also bounded, in the sense that they cannot be negative. Forcing the algorithm to take this property into account is straightforward: we maximize with respect to standard deviations and calculate the variances within the optimization procedure.
} 
To impose the above restrictions on $\alpha, \beta$ and $\delta$, we use the GAUSS module for constrained maximum likelihood estimation version 1.0 (for a detailed description, see Schoenberg (1997)). Since the standard errors for the parameters have to allow for the possibility that the true values are near or actually on the constraint boundaries, we construct bootstrap confidence intervals at the $95 \%$ level.

\section{Econometric Results}

We next present the results of estimating the econometric model setout in Section 3 (see Table 1) as well as the results of impulse response analysis (see Table 2 and Figures 13). Examination of the results in Table 1 reveals that all parameters are significantly different from zero and some interesting cross-country differences. More specifically, the physical productivity of public production services relative to private capital, $(1-\alpha)$, is highest in Germany (0.309) followed by the US (0.279) and the UK $(0.270)$. The difference between Germany and the UK is significant, but the US does not differ

significantly from either country. Estimates of the time discount rate, $\beta$, are 0.954 , 0.978 and 0.986 for the US, Germany and the UK respectively and are all statistically significantly different from each other. The estimates for the weight private consumers place on public consumption services relative to private consumption, $\delta$, are $0.385,0.475$ and 0.600 for the US, Germany and the UK respectively. The UK and German results differ significantly from each other, while the US differs significantly from the UK but not from Germany. 
Table 1: Estimation Results

\begin{tabular}{|c|c|c|c|c|c|c|c|c|c|c|}
\hline \multirow[b]{2}{*}{ Parameter } & \multirow[b]{2}{*}{ Restriction } & \multicolumn{3}{|c|}{ United Kingdom } & \multicolumn{3}{|c|}{ Germany } & \multicolumn{3}{|c|}{ United States } \\
\hline & & $\begin{array}{c}\text { Point } \\
\text { Estimate }\end{array}$ & $\begin{array}{c}\text { Lower } \\
\text { limit }\end{array}$ & $\begin{array}{c}\text { Upper } \\
\text { limit }\end{array}$ & $\begin{array}{c}\text { Point } \\
\text { Estimate }\end{array}$ & $\begin{array}{c}\text { Lower } \\
\text { limit }\end{array}$ & $\begin{array}{l}\text { Upper } \\
\text { limit }\end{array}$ & $\begin{array}{c}\text { Point } \\
\text { Estimate }\end{array}$ & $\begin{array}{c}\text { Lower } \\
\text { limit }\end{array}$ & $\begin{array}{c}\text { Upper } \\
\text { limit }\end{array}$ \\
\hline $\bar{q}$ & 0.5 & - & - & - & - & - & - & - & - & - \\
\hline$\alpha$ & $0.20 \leq 1-\alpha \leq 0.40$ & 0.270 & 0.255 & 0.279 & 0.309 & 0.293 & 0.325 & 0.279 & 0.242 & 0.320 \\
\hline$\beta$ & $0.95 \leq \beta \leq 0.99$ & 0.986 & 0.982 & 0.990 & 0.978 & 0.973 & 0.980 & 0.954 & 0.950 & 0.958 \\
\hline$\delta$ & $0 \leq \delta \leq 1$ & 0.600 & 0.595 & 0.605 & 0.475 & 0.405 & 0.555 & 0.385 & 0.314 & 0.510 \\
\hline$\rho$ & & 0.961 & 0.934 & 0.991 & 0.918 & 0.882 & 0.956 & 0.889 & 0.863 & 0.929 \\
\hline $\bar{\theta}$ & & 0.277 & 0.262 & 0.289 & 0.318 & 0.301 & 0.336 & 0.297 & 0.261 & 0.338 \\
\hline $\bar{b}$ & & 0.972 & 0.966 & 0.980 & 0.970 & 0.959 & 0.976 & 0.941 & 0.915 & 0.955 \\
\hline $\begin{array}{c}\text { Log- } \\
\text { Likelihood }\end{array}$ & & & -2.946 & & & -3.157 & & & -5.428 & \\
\hline$N$ & & & 140 & & & 153 & & & 149 & \\
\hline
\end{tabular}
displayed in column 2 . The $95 \%$ confidence intervals are based on 1000 re-samplings.

We now turn to the estimated policy parameters reported in Table 1. Persistence of political uncertainty, captured by $\rho$ in equation (11), is highest in the UK $(0.961)$ followed by Germany (0.918) and the US (0.889). The UK and German results do not statistically differ from each other, while the US differs significantly from the UK but not from Germany. The estimates for the long-run values of the optimal tax rate $(\bar{\theta})$ and the optimal share of total tax revenues allocated to public production services relative to consumption ones $(\bar{b})$ are all within the ranges predicted by the theory (see equations (13a-13b)). Specifically, the long-run tax rates are $0.277,0.297$ and 0.318 for the UK, the US and Germany respectively. The British and German tax rates $(\bar{\theta})$ are statistically different from each other, but the US does not differ from either of the European countries. Finally, the optimal long-run share of tax revenues allocated to public production services $(\bar{b})$ is $0.941,0.970$ and 0.972 for the US, Germany and the UK respectively. ${ }^{42}$ The British and German values are not significantly different from each other, while the US differs from both the UK and Germany.

\footnotetext{
${ }^{42}$ The estimated long-run values of $\bar{b}$, although consistent with the theory (see equation (13b)), seem to be too high. However, recall that here the engine of perpetual economic growth is public production services as defined in (8b). Also recall that the provision of public (production, consumption, etc) services requires large
} 
To more fully assess the persistence of fluctuations resulting from a change in the probability of being reelected $(q)$, as well as the effects on the steady-state values of the endogenous variables, we next undertake impulse response analysis. To do so, we analyze a temporary positive unit shock to $\hat{q}$. Results are reported in Table 2 .

Table 2: Summary Impulse Response Results

\begin{tabular}{|c|c|c|c|c|c|c|c|c|c|}
\hline \multirow[b]{2}{*}{ Parameter } & \multicolumn{3}{|c|}{ United Kingdom } & \multicolumn{3}{|c|}{ Germany } & \multicolumn{3}{|c|}{ United States } \\
\hline & $\begin{array}{c}\text { Point } \\
\text { Estimate }\end{array}$ & $\begin{array}{c}\text { Lower } \\
\text { limit }\end{array}$ & $\begin{array}{c}\text { Upper } \\
\text { limit }\end{array}$ & $\begin{array}{c}\text { Point } \\
\text { Estimate }\end{array}$ & $\begin{array}{c}\text { Lower } \\
\text { limit }\end{array}$ & $\begin{array}{c}\text { Upper } \\
\text { limit }\end{array}$ & $\begin{array}{c}\text { Point } \\
\text { Estimate }\end{array}$ & $\begin{array}{c}\text { Lower } \\
\text { limit }\end{array}$ & $\begin{array}{l}\text { Upper } \\
\text { limit }\end{array}$ \\
\hline $\begin{array}{c}\text { Standard } \\
\text { deviation of } \\
\text { estimated } \hat{q}\end{array}$ & 0.963 & 0.221 & 1.660 & 0.333 & 0.126 & 0.582 & 0.179 & 0.145 & 0.221 \\
\hline $\begin{array}{l}\text { Long-run } \\
\text { response of } \hat{y}\end{array}$ & 0.375 & 0.107 & 0.838 & 0.355 & 0.184 & 0.640 & 0.933 & 0.464 & 1.547 \\
\hline$t^{*}$ & $\mathbf{1 7 . 4 2 4}$ & 10.152 & 76.670 & 8.102 & 5.520 & 15.404 & 5.891 & 4.704 & 9.412 \\
\hline
\end{tabular}

Notes: $\mathrm{t}^{*}$ : time (quarters) in which the initial shock to $\hat{q}$ halves $\left(t^{*}=\ln (0.5) / \ln (\rho)\right)$. The responses of $\hat{y}$ are based on a unit shock to $\hat{q}$.

As predicted by the theory, Figures 1-3 show that the endogenous policy instruments $\hat{\theta}$ and $\hat{b}$ move in opposite directions. Specifically, in all three countries, as a result of a temporary rise in $\hat{q}, \hat{\theta}$ decreases before monotonically increasing to its steady state (i.e. zero), whereas $\hat{b}$ increases prior to decreasing to its steady state deviation of zero. The confidence bands also suggest that these changes (as well as all changes reported in Figures 1-3) are statistically significant for the duration of the simulation.

Turning to effects of a temporary rise in the re-election probability upon macroeconomic outcomes, we can see for all countries that private consumption and investment ( $c$ and $i$ ), as well as public investment $(g)$, all monotonically increase before converging to new balanced growth paths which are higher than their pre-shock paths. On the other hand, public consumption $(h)$ increases before monotonically decreasing to its

tax bases and this can be achieved by relatively high $\bar{b}$ and low $\bar{\theta}$. This is especially true in the long run where tax bases are fully endogenous. 
new balanced growth path that is higher than the pre-shock one. ${ }^{43}$ If we concentrate on output, the point estimates appear to indicate that long-run growth in the US is relatively most affected by the increase in the re-election probability. For example, Figures 1-3 and Table 2 (see row 2) show that steady-state growth is about 0.4 points higher for the UK and Germany and nearly a point for the US. However, closer inspection of the confidence bands in Table 2 indicates that there is no significant difference between these countries. Nonetheless, an increase in the probability of being re-elected has a statistically significant and positive effect on the steady-state growth rate of output for all countries. Finally, to demonstrate the relative importance of the four components of output $(c, i, g$ and $h)$ in the transmission of a shock to $\hat{q}$ to output growth, Figure 4 contains a decomposition of the output growth response into the contributions of each component.

Figure 1: Percentage Deviation Responses to a Unit Shock to $\hat{q}$

(United Kingdom)
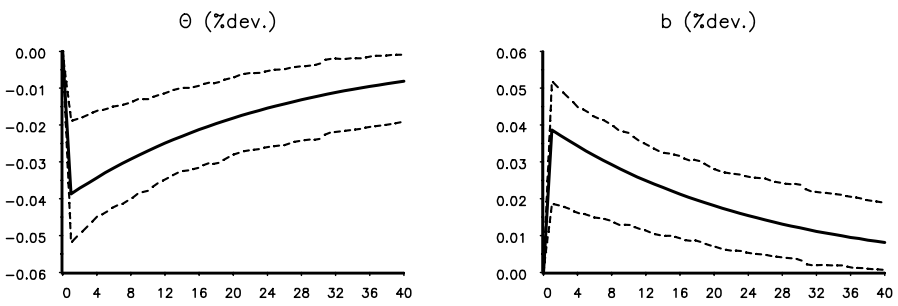

$c, i(\%$ dev.)

g (\%dev.)
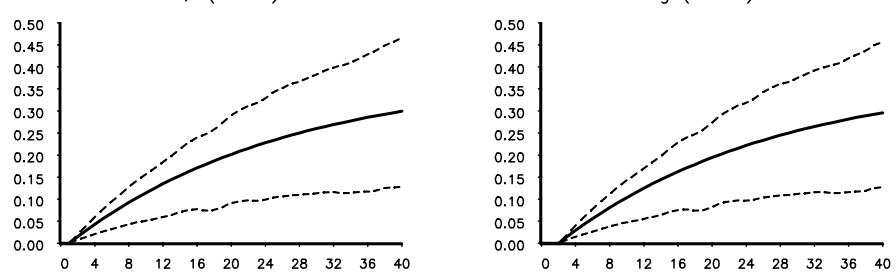

h $(\%$ dev.)

y (\%dev.)
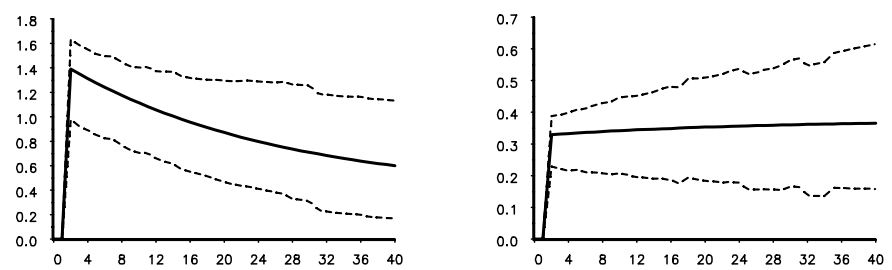

\footnotetext{
${ }^{43}$ Recall that this is a model of endogenous growth (an $A K$ model). This means that even temporary shocks in fiscal policy can have permanent effects on levels and growth rates (see also e.g. King and Rebelo (1990), Ambler and Paquet (1996) and Gemmel and Kneller (2001)).
} 
Figure 2: Percentage Deviation Responses to a Unit Shock to $\hat{q}$ (Germany)

$\Theta(\%$ dev.)

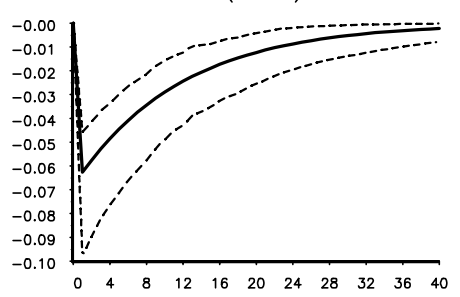

c,i (\%dev.)
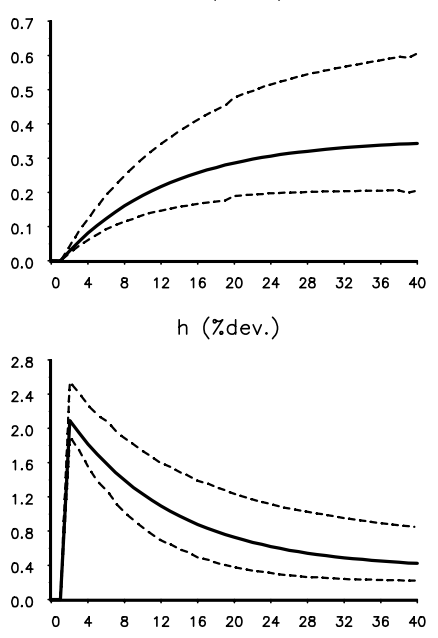

b (\%dev.)

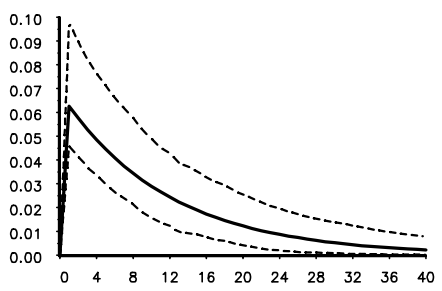

g (\%dev.)
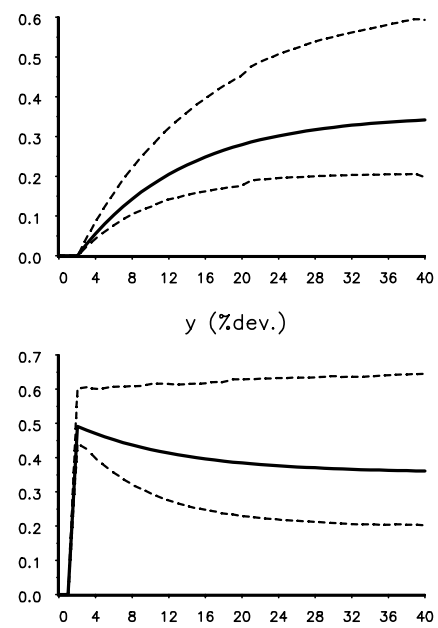

Figure 3: Percentage Deviation Responses to a Unit Shock to $\hat{q}$ (United States)

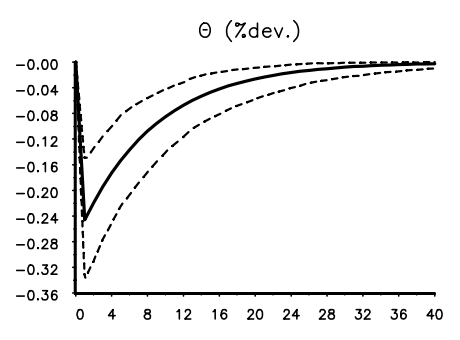

c,i (\%dev.)
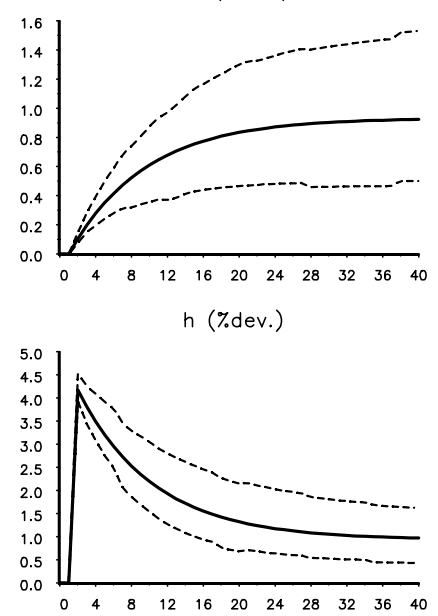

b (\%dev.)

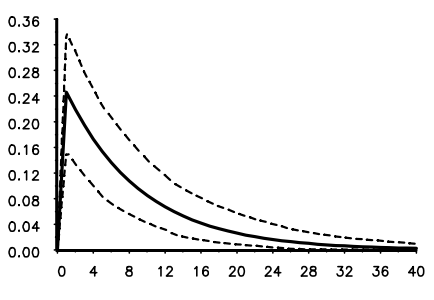
g (\%.dev.)
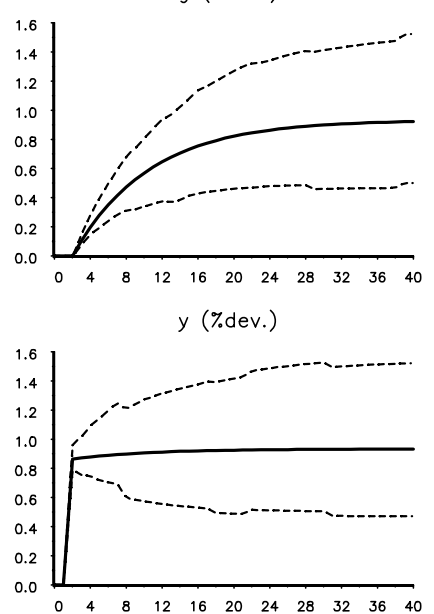
Figure 4: Relative Contribution of Components of $\hat{y}$ to Output Growth Response
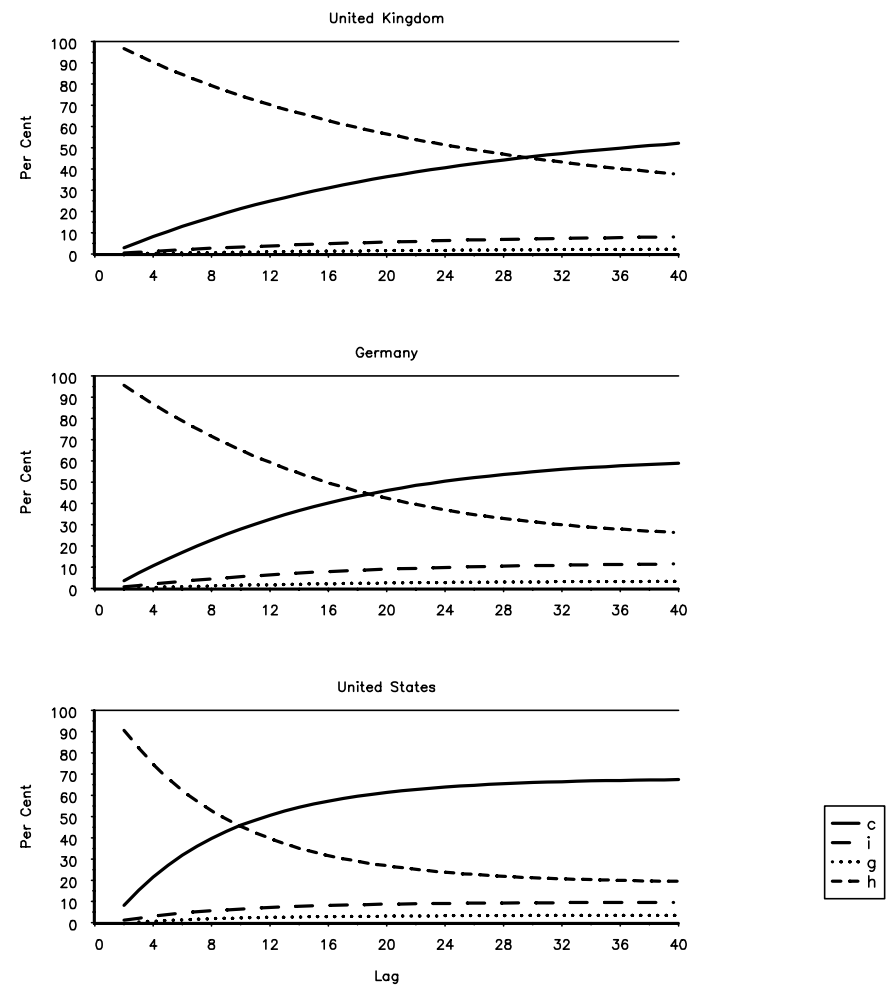

We now return to the issue pertaining to the persistence of shocks discussed in relation to the estimates of $\rho$ in Table 1. Table 2 (see row 3 ) shows the time (in quarters) it takes for the initial shock to $\hat{q}$ to half. The point estimates suggest that it takes approximately 4 years for the UK, 2 years for Germany and 1.5 years for the US. ${ }^{44}$ Broadly speaking, this rank ordering is consistent with business cycle stylized facts, i.e. the US cycle is shorter, which is reflected in the lower modulus/higher damping that we find (see, e.g., Zarnowitz op cit. and Woitek op cit.).

\section{Conclusions}

This paper has solved and estimated a tractable dynamic stochastic general equilibrium model to study the link between elections, fiscal policy and

\footnotetext{
${ }^{44}$ Note however that the confidence bands for the US and Germany overlap.
} 
fluctuations/growth. The model was formally estimated for Germany, the UK and the US, which are generally believed to be the economies closest to the neoclassical paradigm. The focus has been on the effects of electoral uncertainty and party competition upon the choice of fiscal policy instruments and in turn upon the macro-economy. The main result is that electoral competition pushes governments to follow relatively short-sighted fiscal policies and this is detrimental for the macro-economy. Our econometric results provide clear support for this proposition from both fluctuations and growth perspectives. By explicitly modeling the channel through which political uncertainty affects the economy, we found a statistically significant effect of electoral uncertainty on output growth. This effect is small in magnitude, which might help to explain why previous empirical studies can at best identify a political business cycle in policy instruments.

Our research contributes to both the literature on political business cycles, as well as the quantitative RBC literature. It adds to the former mainly because, to the extent that we formally estimate the solution of the theoretical model, we fill the gap between theoretical and empirical research. To date, there has been very little econometric work, which has successfully made the formal link between political uncertainty, endogenous fiscal policy and ultimately aggregate outcomes. Our research also adds to the RBC literature mainly because, instead of relying only on non-sample information, we combine this with observed data to obtain estimated values of a number of parameters which are of key interest in a variety of general equilibrium modeling contexts. 


\section{References}

Ambler S. and A. Paquet (1996): Fiscal spending shocks, endogenous government spending and real business cycles, Journal of Economic Dynamics and Control, 20, 237-256.

Alesina A. (1999): Too large and too small governments, in Economic Policy and Equity, edited by V. Tanzi, K. Chu and S. Gupta. International Monetary Fund, Washington, D. C.

Alesina A., N. Roubini and G. Cohen (1997): Political Cycles and the Macroeconomy. MIT Press, Cambridge, Mass .

Alesina A. and J. Sachs (1988): Political parties and business cycle in the US 1948-84, Journal of Money, Credit and Banking, 20, 63-82.

Alesina A. and G. Tabellini (1990): A positive theory of fiscal deficits and government debt, Review of Economic Studies, 57, 403-414.

Alogoskoufis G., B. Lockwood and A. Philippopoulos (1992): Wage inflation, electoral uncertainty and the exchange rate regime: theory and UK evidence, Economic Journal, 102, 1370-1394.

Baier S. and G. Glomm (2001): Long-run growth and welfare effects of public policies with distortionary taxation, Journal of Economic Dynamic and Control, 25, 2007-2042.

Barro R. (1990): Government spending in a simple model of endogenous growth, Journal of Political Economy, 98, S103-S125.

Barro R. and X. Sala-i-Martin (1995): Economic Growth. McGraw Hill, New York.

Baxter M. and R. King (1993): Fiscal policy in general equilibrium, American Economic Review, 83, 315-334.

Benhabib J., A. Rustichini and A. Velasco (2001): Public spending and optimal taxes without commitment, Review of Economic Design, 6, 371-396.

Campbell J. (1993): Intertemporal asset pricing without consumption data, American Economic Review, 83, 487-511.

Campbell J. (1994): Inspecting the mechanism: An analytical approach to the stochastic growth model, Journal of Monetary Economics, 33, 463-506.

Campbell J. and L. Viceira (2002): Strategic Asset Allocation. Oxford University Press, Oxford.

Carmignani F. (2003): Political instability, uncertainty and economics, Journal of Economic Surveys, 17, 1, 1-54.

Demetriades P. and T. Mamuneas (2000): Intertemporal output and employment effects of public infrastructure capital: evidence from 12 OECD economies, Economic Journal, 110, 687-712.

Devarajan S., V. Swaroop and H. Zou (1996): The composition of public expenditure and economic growth, Journal of Monetary Economics, 37, 313-344. 
Devereux M. and J-F. Wen (1998): Political instability, capital taxation and growth, European Economic Review, 42, 1635-1651.

Dixit A., G. Grossman and F. Gul (2000): The dynamics of political compromise, Journal of Political Economy, 108, 531-568.

Drazen A. (2000): Political Economy in Macroeconomics. Princeton University Press, Princeton.

Economides G., A. Philippopoulos and S. Price (2003): Elections, fiscal policy and growth: Revisiting the mechanism, forthcoming in the European Journal of Political Economy.

Fudenberg D. and J. Tirole (1991): Game Theory. MIT Press. Cambridge, Mass.

Gemmell N. and R. Kneller (2001): The impact of fiscal policy on long-run growth, European Economy, 1, 99-129.

Glomm G. and B. Ravikumar (1994): Public investment in infrastructure in a simple growth model, Journal of Economic Dynamics and Control, 18, 1173-1187.

Glomm G. and B. Ravikumar (1997): Productive government expenditures and long-run growth, Journal of Economic Dynamics and Control, 21, 183-204.

Guo J.-T. and K. Lansing (1999): Optimal taxation of capital income with imperfectly competitive product markets, Journal of Economic Dynamics and Control, 23, 967-995.

Harvey A.C. (1993): Time Series Models. Harvester Wheatsheaf, New York. 2nd ed.

King R. and S. Rebelo (1990): Public policy and economic growth: developing neoclassical implications, Journal of Political Economy, 98, S126-S150.

Klein P., V. Quadrini and J.-V. Rios-Rull (2003): Optimal and time-consistent fiscal policy with international mobility of capital: Why does the US rely on capital taxes more than Europe?, International Economic Review, forthcoming.

Kneller R., M. Bleaney and N. Gemmell (1999): Fiscal policy and growth: evidence from OECD countries, Journal of Public Economics, 74, 171-190.

Lansing K. (1998): Optimal fiscal policy in a business cycle model with public capital, Canadian Journal of Economics, 31, 337-364.

Ljungqvist L. and T. Sargent (2000): Recursive Macroeconomic Theory. The MIT Press, Cambridge, Mass.

Lockwood B., A. Philippopoulos and A. Snell (1996): Fiscal policy, public debt stabilization and politics: theory and UK evidence, Economic Journal, 106, 894-911.

Lucas R. E., Jr. (1990): Supply side economics: an analytical review, Oxford Economic Papers, 42, 293-316. 
McCallum B. (1989): Real business cycle models, in Modern Business Cycle Theory, edited by R. Barro. Blackwell, London.

McGrattan E. (1994): The macroeconomic effects of distortionary taxation, Journal of Monetary Economics, 33, 573-601.

Park H. and A. Philippopoulos (2003): On the dynamics of growth and fiscal policy with redistributive transfers, Journal of Public Economics, 87, 515-538.

Park H. and A. Philippopoulos (2004): Indeterminacy and fiscal policies in a growing economy, Journal of Economic Dynamics and Control, forthcoming.

Persson T. and L. Svensson (1989): Why a stubborn conservative would run a deficit: policy with time-inconsistent preferences, Quarterly Journal of Economics, 104, 325-345.

Persson T. and G. Tabellini (1999): Political economics and macroeconomic policy, in Handbook of Macroeconomics, vol. 1C, edited by J. Taylor and M. Woodford. North-Holland, Amsterdam.

Persson T. and G. Tabellini (2000): Political Economics: Explaining Economic Policy. MIT Press. Cambridge, Mass.

Price S. and D. Sanders (1994): Economic competence, rational expectations and government popularity in post-war Britain, Manchester School, 62, 296-312.

Rogoff K. (1990): Equilibrium political budget cycles, American Economic Review, 80, 21-36.

Rogoff K. and A. Sibert (1988): Elections and macroeconomic policy cycles, Review of Economic Studies, LV, 1-16.

Sargent T. (1987): Dynamic Macroeconomic Theory. Harvard University Press, Cambridge, Mass.

Schoenberg R. (1997): Constrained Maximum Likelihood, Computational Economics, 10, 251 266.

Stokey N. and R. Lucas (1989): Recursive Methods in Economic Dynamics. Harvard University Press, Cambridge, Mass.

Svensson J. (1998): Investment, property rights and political instability: Theory and evidence, European Economic Review, 42, 1317-1341.

Tanzi V. and Schuknecht L. (2000): Public spending in the $20^{\text {th }}$ century. Cambridge University Press, Cambridge.

Woitek U. (1996): The G7-Countries: A multivariate description of business cycle stylized facts, in Dynamic Disequilibrium Modelling: Theory and Applications, edited by W. Barnett, G. Gandolfo and C. Hillinger. Cambridge University Press, Cambridge.

Zarnowitz V. (1992): Business Cycles: Theory, History, Indicators and Forecasting. University of Chicago Press, Chicago. 


\section{Appendices}

\subsection{Appendix A: Result 1}

This appendix solves for a Competitive Decentralized Equilibrium (CDE) as defined in the text. Note that the household's problem is only a part of this CDE. The log-linear objective (1a)-(1b), the Cobb-Douglas functional forms for the production function in (9) and government consumption services in (10d), and the assumption that policy instruments $\left(\theta_{t}\right.$ and $\left.b_{t}\right)$ are Markov, imply a value function of the form $V\left(k_{t} ; \theta_{t}, b_{t}\right)=u_{0}+u_{1} \log k_{t}+u_{2} \theta_{t}+u_{3} b_{t}$, where $\left(u_{0}, u_{1}, u_{2}, u_{3}\right)$ are time-invariant undetermined coefficients. Substituting this conjecture for the value function into the optimality conditions (4a) and (4b), and using (7a) and (9), we get (10b). Then, (10a) follows from (10b) and (2). See also e.g. McCallum (1989, equations (1.16-1.21) for a similar solution.

We now have to solve for $\left(u_{0}, u_{1}, u_{2}, u_{3}\right)$ and verify our conjecture for the value function. To do so, we substitute (10a), (10b) and (10d) back into (3) and equate coefficients on both sides of the Bellman. For instance, by equating coefficients on $\log k_{t}$, the Riccati equation for $u_{1}$ gives $u_{1}=\frac{1+\delta}{1-\beta}>0$. Notice that $u_{1}$ is the crucial coefficient; namely, it is the coefficient that matters for the optimal decisions, $\left(c_{t}, k_{t+1}\right)$, in (4a)-(4b). The other undetermined coefficients $\left(u_{0}, u_{2}, u_{3}\right)$ may matter for the solution of the value function, but not for $\left(c_{t}, k_{t+1}\right)$. Hence, we will only sketch their solution here. To solve for $\left(u_{0}, u_{2}, u_{3}\right)$, we need to contend with $\log \theta_{t}, \log \left(1-\theta_{t}\right), \log b_{t}$ and $\log \left(1-b_{t}\right)$ [recall that we have substituted (10a), (10b) and (10d) for $c_{t}, k_{t+1}$ and $h_{t}$ back into the Bellman in (3)]. To do so, we take first-order Taylor approximations of $\theta_{t}$ and $b_{t}$ around their longrun values, denoted as $\bar{\theta}$ and $\bar{b}$ (see Appendix $\mathrm{B}$ below for $\bar{\theta}$ and $\bar{b}$ ). That is, we have 
$\log \theta_{t} \cong \log \bar{\theta}+\frac{1}{\bar{\theta}}\left(\theta_{t}-\bar{\theta}\right), \quad \log \left(1-\theta_{t}\right) \cong \log (1-\bar{\theta})-\frac{1}{(1-\bar{\theta})}\left(\theta_{t}-\bar{\theta}\right) \quad$ and $\quad$ similar expressions for $\log b_{t}$ and $\log \left(1-b_{t}\right)$. Using these approximations into (3), and if the policy instruments $\left(\theta_{t}\right.$ and $\left.b_{t}\right)$ are Markov, we can equate coefficients on both sides of the Bellman to get Riccati equations for $\left(u_{0}, u_{2}, u_{3}\right)$. It is important to point out that those solutions for $\left(u_{0}, u_{2}, u_{3}\right)$ can be obtained only after we solve for optimal policy, $\theta_{t}$ and $b_{t}$ (see Appendix B below). This is how it should be, since this is a general equilibrium model in which policy instruments are chosen endogenously [see also Economides et al. (2003)]. By contrast, if policy were exogenous, we could simply assume (exogenous) statistical processes driving $\theta_{t}$ and $b_{t}$ over time. This also verifies (approximately) our conjecture for the value function.

\subsection{Appendix B: Result 2}

We conjecture that the two value functions in (12a)-(12b) take the form $V^{P_{i}}\left(k_{t} ; q_{t}\right)=u_{0}^{P}+u_{1}^{P} \log k_{t}+u_{2}^{P} q_{t} \quad$ and $\quad V^{N_{i}}\left(k_{t} ; q_{t}\right)=u_{0}^{N}+u_{1}^{N} \log k_{t}+u_{2}^{N} q_{t}$, where $\left(u_{0}^{P}, u_{1}^{P}, u_{2}^{P}, u_{0}^{N}, u_{1}^{N}, u_{2}^{N}\right)$ are time-invariant undetermined coefficients. Party $j$ solves a symmetric problem, so that we have two pairs of equations like (12a)-(12b). We will solve party $i$ 's problem. If we use the above conjectures into (12a)-(12b), differentiate the righthand side of (12a) with respect to the controls $\theta_{t}^{i}$ and $b_{t}^{i}$, and impose the ex post symmetry conditions $\theta_{t}^{i}=\theta_{t}^{j} \equiv \theta_{t}, b_{t}^{i}=b_{t}^{j} \equiv b_{t}, u^{P i}=u^{P j} \equiv u^{P}$ and $u^{N i}=u^{N j} \equiv u^{N}$, then the firstorder conditions for $\theta_{t}$ and $b_{t}$ in a symmetric Nash equilibrium in Markov strategies are (13a) and (13b) respectively, where $E_{t} \Omega_{t+1} \equiv 1+\beta\left[u_{1}^{P} E_{t} q_{t+1}+u_{1}^{N}\left(1-E_{t} q_{t+1}\right)\right]>0$.

We now have to solve for $\left(u_{0}^{P}, u_{1}^{P}, u_{2}^{P}, u_{0}^{N}, u_{1}^{N}, u_{2}^{N}\right)$ and verify our conjecture for the value functions. To do so, we substitute (13a)-(13b) back into (12a)-(12b) by using (10a), 
(10b) and (10d), and then equate coefficients on both sides of the two Bellman equations (12a)-(12b). The crucial coefficients are $u_{1}^{P}, u_{1}^{N}$. Namely, these are the coefficients that solve $E_{t} \Omega_{t+1}$ and hence matter in the solution for the optimal strategies in (13a)-(13b). Equating coefficients on $\log k_{t}$ in (12a)-(12b), we obtain two Riccati equations, $u_{1}^{P}=1+\delta+\beta\left[u_{1}^{P} E_{t} q_{t+1}+u_{1}^{N}\left(1-E_{t} q_{t+1}\right)\right]$ and $u_{1}^{N}=\beta\left[u_{1}^{P}\left(1-E_{t} q_{t+1}\right)+u_{1}^{N} E_{t} q_{t+1}\right]$, which can be solved for $u_{1}^{P}$ and $u_{1}^{N}$. Their solution gives $E_{t} \Omega_{t+1}=\frac{(1+\delta)\left(1-\beta E_{t} q_{t+1}\right)}{(1-\beta)\left(1+\beta-2 \beta E_{t} q_{t+1}\right)}-\delta>0$

The solution for the rest of undetermined coefficients $\left(u_{0}^{P}, u_{2}^{P}, u_{0}^{N}, u_{2}^{N}\right)$, and hence for the value functions, will be based on first-order Taylor approximations around long-run values. Notice that $\left(u_{0}^{P}, u_{2}^{P}, u_{0}^{N}, u_{2}^{N}\right)$ do not affect the optimal strategies, $\left(\theta_{t}, b_{t}\right)$, in (13a)(13b). Since they are not of particular interest, we will only sketch their solution here. Using (13a), we get $\log \theta_{t} \cong \log \bar{\theta}+\left[\frac{(1-\alpha)}{\delta+(1-\alpha) \bar{\Omega}}-\frac{1}{\delta+\bar{\Omega}}\right] \frac{\partial \bar{\Omega}}{\partial \bar{q}}\left(E_{t} q_{t+1}-\bar{q}\right) \quad$ and $\log \left(1-\theta_{t}\right) \cong \log (1-\bar{\theta})+\frac{\delta}{(\delta+\bar{\Omega}) \bar{\Omega}} \frac{\partial \bar{\Omega}}{\partial \bar{q}}\left(E_{t} q_{t+1}-\bar{q}\right), \quad$ where $\quad \bar{\theta}=\frac{\delta+(1-\alpha) \bar{\Omega}}{\delta+\bar{\Omega}}$, $\bar{\Omega}=\frac{(1+\delta)(1-\beta \bar{q})}{(1-\beta)(1+\beta-2 \beta \bar{q})}-\delta, \frac{\partial \bar{\Omega}}{\partial \bar{q}}=\frac{(1+\delta) \beta}{(1+\beta-2 \beta \bar{q})^{2}}$ and $\bar{q}$ denotes the long-run value of $q_{t}$. Working similarly and using (13b), we can get analogous approximations for $\log b_{t}$ and $\log \left(1-b_{t}\right)$. This implies that $\log \theta_{t}, \log \left(1-\theta_{t}\right), \log b_{t}$ and $\log \left(1-b_{t}\right)$ are linear functions of $E_{t} q_{t+1}$ only. Also notice that $E_{t}\left(q_{t+1}^{2}\right) \cong \bar{q}^{2}+2 \bar{q}\left(E_{t} q_{t+1}-\bar{q}\right)$, where $E_{t} q_{t+1}=q_{0}+\rho q_{t}$. Thus, we only have intercepts and terms with $q_{t}$ on the RHS of (12a)(12b). We can therefore equate coefficients on $q_{t}$ and intercepts on both sides of (12a)- 
(12b) to get Riccati equations for $\left(u_{0}^{P}, u_{2}^{P}, u_{0}^{N}, u_{2}^{N}\right)$. This also verifies (approximately) our conjecture for the value functions.

Notice that this also completes the solution of the competitive decentralized equilibrium in Appendix A. This is because $\theta_{t}$ (the same arguments apply to $b_{t}$ ) on the LHS of the Bellman in (3) is a function of $E_{t} q_{t+1}$ and hence [since $E_{t} q_{t+1}=q_{0}+\rho q_{t}$ ] a linear function of $q_{t}$, while $E_{t} \theta_{t+1}$ on the RHS of (3) is a function of $E_{t} q_{t+2}$ and hence [since $E_{t} q_{t+2}=(1+\rho) q_{0}+\rho^{2} q_{t}$ ] also a linear function of $q_{t}$. Accordingly, we can equate coefficients on both sides of the Bellman to solve for $\left(u_{0}, u_{2}, u_{3}\right)$ in the private agents' problem. 